man. Their removal would destroy desire and diminish the wants of nature. A want removed is equivalent to a want supplied. It would be a kindness rather than an injury to abnormal persons. The operation is simple, safe and painless. It would confer upon inmates of prisons, reformatories, etc, immunity from evil practices, and give them health and strength, satisfaction and comfort for discontent and insatiable desire. The prevention of reproduction should not be objectionable to this class, because idiotic, insane or criminal children are of no comfort to parents. Such surgery is as wise and merciful as vaccination or the extraction of a decayed and aching tooth.

In the Cincinnati Lancet-Clinic, Oct. 3, 1896, will be found a description of an operation invented by the writer for the cure of certain cases of insanity. The operation consists in cutting or exsecting from one-fourth to one-half inch of certain branches of the pudic nerve. This causes a suspension of the sexual activities for a period of from one to four years, with a return of same as soon as the nerves are reunited. This operation has not been in use long enough to judge of its usefulness. The sexual instinct was implanted for the propagation of the race, not for its degeneration and destruction. Humanity sins against the Creator by contributory neglect in this matter. Society arrests and confines the lepers, the victims of smallpox, yellow fever or cholera, and treats them as it sees fit. It shuts up the imbecile, the criminal and the insane for the protection of the public. No on $\theta$ questions its right to do so. Yet it allows the deformed and diseased in mind and body and soul to disseminate social leprosy and cancer. This could be prevented by the adoption of an operation almost as simple and painless as vaccination. It seems strange that the matter should be delayed so long. Asylums, prisons, and jails can not be built fast enough to meet the requirements of social neglect. Society is working at the wrong end of the subject. It should get at the rottenness of the root of the tree of human. ity. The upper tenth in society has remained about the same for 3000 years. There used to be no submerged tenth, but today we have a largely increasing submerged tenth. There is a lack of growth at the top. Stature and health are decreasing. Weak nerves and weak stomachs are on the increase, as the result of faulty breeding. The decay of the Republic is due to the degeneracy of the people. It is an outrage that the State and Nation stand idly by and permit the intermarriage of criminals, paupers and defectives, thus becoming a party to the wholesale manufacture of probable criminals. The State has the right and power to prevent the probable from becoming the positive criminal.

History records that many cities have been built on this earth, some of them nearly as large and as rich as any of the present age, yet through internal disease they went down in ruin, and nothing but potsherds and broken brick remain to mark their former existence. It is time to put up the signboard and sug. gest whither we are drifting.

Let the nation adopt the plan of treatment herein suggested for one generation, and the result would be that all the inherited rottenness and corruption of ages would be purged out of the people, The crim. inal and pauper class would become extinct. Asylums, prisons and jails would become depopulated. The great burden of taxation would be lifted from the people. Doctor's bills would be less of a drain upon the family and chronic disease would be diminished. Let the sword of justice cut the knot of bondage and let society take control of its own destiny and regulate reproduction with the wisdom of expe. rience, and the "ills which flesh is heir to" will vanish before the glorious dawn of the day of comfort, hope, peace and promise.

Fifth and Wilkinson Streets.

BIBLIOGRAPHY.

Havelock Ellis: The Criminal.

Morrison: The Criminal.

Morrison: Female Offender.

Morrison: Civilization; Cause and ('ure.

Fairbanks: Introduction to sociology.

F. M. Sprague: The Laws of Social Fvolution.

Boies: Criminals and Paupers.

Reports from Elmira Reformatory.

Clouston: Mental Diseases,

Bevan-Lewis: Mental Diseases.

Tuke: Mental Diseases.

Sterns: Mental Diseases.

Sterns: Insanity; Its Causes and Prevention.

Lombro:o: Insanity and Genius.

\section{A CASE OF ACROMEGALY.}

Presented to the Section on Neurology and Medical Jurisprudence, at the Forty-ninth Annual Meeting of the American Medical Association, held at Denver, Colo,, June 7-10, 1898.

BY HENRY WALDO COE, M.D.

Physician-in-Charge, Mindsease Sanitarium; Consulting Neurologist to the Oregon State Institutions for the Deaf, Dumb and Blind, etc. PORTLAND, OREGON.

Although acromegaly was first described as a medical entity in 1886, since that time (Woods Hutchinson) two hundred and fifty cases have been reported, of an average of about twenty per year. When it is taken into account that probably at least one-half of these reported cases, like the one herewith submitted, were recognized, although not classified, before Marie brought the subject into prominence, it may not be deemed unreasonable to say that, the world over, ten represents the number of cases annually developing into the malady of acromegaly, and that it is, therefore, one of the rarest diseases known. The subject of acromegaly has been scientifically presented by numerous investigators quite recently, a list of several of the latest of these papers being found at the close of this report, and for the purpose of increasing the number of reported cases and to enhance the value of the more scientific papers on the subject, the following is briefly given:

Case 1.-Mrs. F. B., German extraction, aged 68, married, occupation, farm wife. Father living, in good health, aged 93. Mother, who had always been in good health, died re. cently at the age of 91 . Several brothers and sisters are living, and all are, as far as can be determined, in good health, but each of these has a highly developed nervous system. All the members of the family are above the average in size, but no giantism or acromegaly is elsewhere reported. A negative history presented of tuberculosis, heart or other organic dis. ease elsewhere in the family, while there is no special history of former serious illness in the patient herself.

Nothing abnormal was discovered in her physical condition until 50 years of age, when the irritability of the nervous sys tem, characteristic of the family, began to be more pronounced and defect in the exercise of normal will-power more manifest. The normal processes of cerebration declined rapidly, and on Feb. 21, 1893, she became so homicidal that she was committed to the Oregon Insane Asylum at Salem, where she has since remained. To Dr. D. A. Pain, the superintendent of that in. stitution, I am largely indebted for much of the data making up this report. At the time of examination for commitment the physician making the same reported as follows: "This patient is a large, fleshy woman, with the vegetative functions well performed. Her lungs and heart are normal, as are all the organs so far as can be determined. Mentally, all the perceptions are normal. Her emotions are moved to great rage without provocation, or to great affection, although the latter much more rarely. Her intelligence is limited and she is incoherent in speech. Her will controls her only in mani- 
festing her physical wants. She is abusive in her language, and sometimes violent with her hands."

No record was made at the asylum at that time of any special deformity of any portion of her body, and as the report of the examining physician of the committing court seems to show that a careful examination was made by him, and as he says that she was physically in a normal condition, we may therefore reasonably presume that acromegalous enlargement and deformity were not at the time present, or if so, in so slight a degree as to be unnoticeable. The incoherence, however, may have been a lingual ataxia from an enlargement of the tongue, already beginning at that time.

Three years later, the hospital reports spoke of the tongue as "large," and also that the "feet and hands are larger than usual." At this time such report also says, "bowels regular." Good pulse. At irregular intervals her face and neck became congested. Coarse, loud, vicious, and profane in speech, which is in a coarse, low-pitched voice. Delusions and hallucinations. Her general condition remained much the same, her mental state showing increased impairment, and on June 6 1889 , we find that she was reported as well-nourished, with bodily functions fairly well performed, and that she had con stant delusions, illusions and hallucinations, although she did

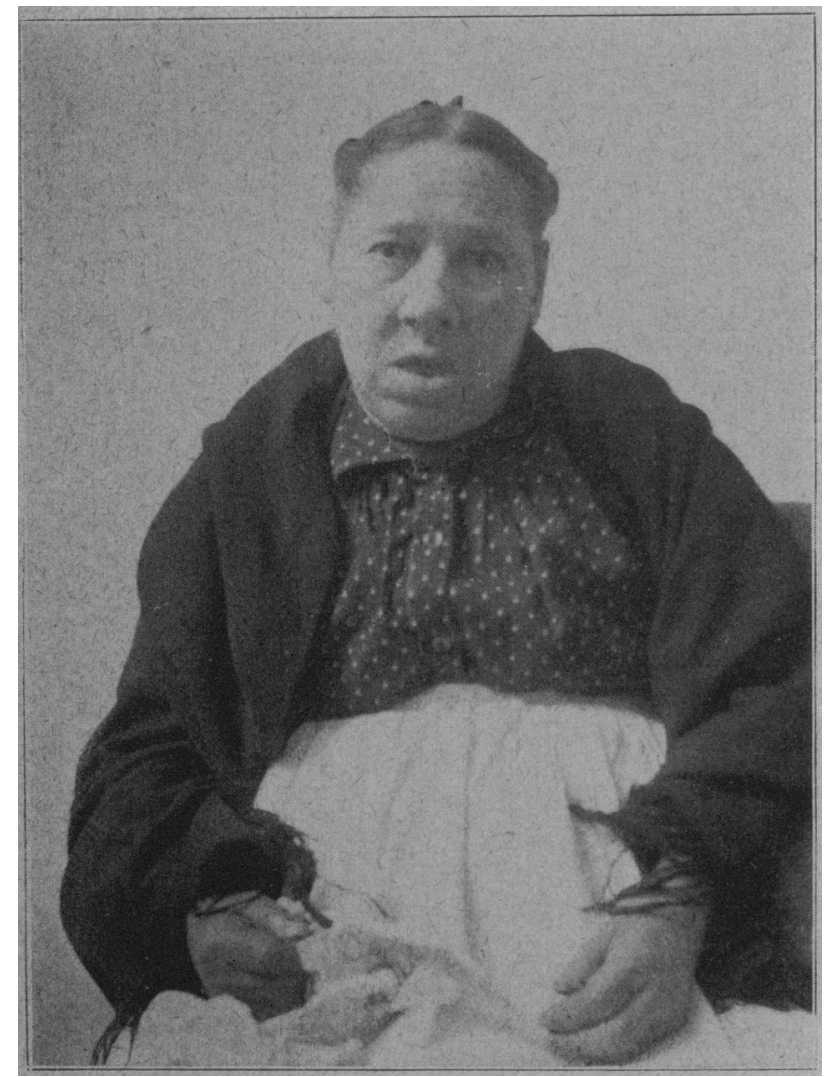

not always obtrude them. Occasionally she was noisy, ex cited, abusive and violent, and her reasoning power and memory were defective.

Five years later, June, 1894, her physical condition was good, all functions being well performed. "Face, hands, feet and body generally enlarged. The tongue being too large to remain ordinarily within the mouth, is always protruded when she sleeps. Excitable and violent. Locomotion somewhat impaired, and no particular desire to move." At the present time she is able to walk only with much difficulty, from general weakness and ataxia. She prefers to, and does, sit in large arm rocking chair most of the time. She has delusions, one of which has been fixed for many years, that is, that her former "neat, tidy and small body was stolen, and they put me in this big, ugly body." She is well-nourished, eating and sleeping well. Her extremities have shown further growth, and her hair has notably grown coarse during recent time. Most of the joints are normal, although all the metacarpophalangeal articular extremities are enlarged. Soft parts of the fingers enlarged, of sausage character. The inferior max illa has grown prominently forward, and the teeth in closing extend beyond the upper three-fourths of an inch. Zygo- matic arches somewhat prominent, and the nose and ears larger than normal. The superciliary arches protrude slightly. The spine is normal. The thyroid is small, the thymus not discernible. The sternum is increased in size, and the whole chest enlarged. The clavicles are thickened. She is strong and vigorous in general appearance, and weighs 202 pounds. Her present height is 5 feet $51 /$ inches. Length of arm : axillary fold to tip of finger, $241 / 2$ inches. Length of middle finger, $3 \frac{1}{2}$ inches. The thumbs seem shorter than they should be, relative to the fingers. Finger nails coarse and thick. The circumference of the head is 22 inches.

There is no sugar in the urine, and Dr. J. T. Williamson says that there is no record of any diabetic symptoms having been present since his connection with the case, eleven years ago. Her pulse is usually rapid and her respiration slow. She has a blowing murmur with the second sound of the heart.

A feature of possible etiologic interest in this case is that the father and mother were first cousins.

\section{BIBLIOGRAPHY.}

Acromezaly, Exophthalmic Goitre, Phthisis Glycosuria, Dr. Geo. R. Murray.

A A case of

Acromegaly: Necropsy, Norman Daiton, Lancet, May 22, 1897 Two Cases of Acromegaly, H. Gifford, M. D. Wes. Med. Review, June, 1897.

Skiagraphs of Acromegaly, Dr. O. L. Schmidt. Medicine, July, 1897. A Case of Acromegaly, O. Osborne, M.D. Yale Med. Jour. Nov., 1897 Treatment of Acromegaly by Extracts of Thyroid and Pituitary Glands Simultaneously, H. D. Rolleston. Lancet, Dec. 4, 1897.

The Brain and Spinal Cord from a Case of Acromegaly, Wm. A. Spilr, M.D.

Report before Phila. Neurological Society. Journal of Mental and Nervous Diseases. January, 1898.

A Case of Acromegaly, A. Ferree Wilmer, M.D. Int. Med. Magazine,

A Case of Acromegaly, Dr. A. Ferree Whitmer. Jour. of Nervous and ental Diseases, January, 1898.

The Pituitary Gland as a Factor in Acromegaly and Giantism, Woods Atchinson, M.D. Med. Jour.. March 12 and Aprif, 1898. $D$ Western Acromegaly in Nebraska.

( York Med. Journal, April 2, 1898.

\section{THE ARTIFICIAL FEEDING OF INFANTS IN GASTRO-INTESTINAL DISTURBANCES.}

Presented to the Section on Diseases of Children, at the Forty-ninth Annual Meeting of the American Medical Association, held at Denver, Colo., June 7-10, 1898.

BY J. M. G. CARTER, M.D., Sc.D., Ph.D.

Professor of Clinical and Preventive Medicine in the College of Physicians and Surgeons, Chicago (School of Medicine, University of Illinois); Fellow of the American Academy of Medicine; Late President of the Illinois State Medical Society, etc. WAUKEGAN, ILL.

Careful study of artificial feeding must be made in two classes of patients; 1 , infants whose mother's milk does not agree; and 2, whose mothers are unable to nurse them. Some of these cases may be supplied by a wet nurse and perhaps everything pass along satisfactorily; but so much trouble is sometimes experienced with wet nurses and so much success attends artificial feeding by means of cow's milk, that many physicians today have almost entirely abandoned the wet-nurse method of feeding babies, especially in view of the fact that it is often difficult to secure a wet nurse whose constitutional history is entirely satisfactory.

In every case it is necessary to determine the cause of disturbance. Not until this is done is the physician in a position to permit or advise the adoption of an artificial diet. The most common cause of digestive derangements in infants is some fault in the feeding. There are at least four factors in this cause, one or more of which are usually present: 1 , the food may be poor in quality: 2 , it may be deficient or too abundant in quantity; 3 , the interval between feedings may be too short or too long; 4, the food may not be of proper temperature. Rarely, cases of congenital mal. formation or imperfect development of the secretory apparatus of the stomach may cause trouble, even 